\title{
Numerical Investigation of the Influence of Blade Helicity on the Performance Characteristics of Vertical Axis Tidal Turbines
}

Philip Marsh ${ }^{1 a}$, Dev Ranmuthugala ${ }^{2}$, Irene Penesis ${ }^{1}$ and Giles Thomas ${ }^{3}$

${ }^{1}$ National Centre for Maritime Engineering and Hydrodynamics, Australian Maritime College, University of Tasmania. Locked Bag 1395, Launceston Tasmania 7250, Australia

${ }^{2}$ National Centre for Ports and Shipping, Australian Maritime College, University of Tasmania. Locked Bag 1397, Launceston Tasmania 7250, Australia

${ }^{3}$ UCL Mechanical Engineering, University College London, Torrington Place, London WC1E 7JE

aCorresponding author: marshp@ amc.edu.au. Locked Bag 1395, Launceston Tasmania 7250, Australia. Phone: (+61) 401639059

Abstract: Previous research has shown that vertical axis helical turbines exhibit lower torque fluctuation levels than straight-bladed turbines; however little is known of the impact of blade helicity on turbine performance characteristics. To investigate these relationships the hydrodynamic characteristics of straight and helical bladed vertical axis turbines were investigated using ThreeDimensional (3D) Computational Fluid Dynamics (CFD) models using a commercial Unsteady Reynolds Averaged Navier Stokes (URANS) solver. Simulations of power output, torque oscillations, and mounting forces were performed for turbines with overlap angles from $0^{\circ}$ to $120^{\circ}$ and section inclination angles from $-15^{\circ}$ to $45^{\circ}$. Results indicated that straight bladed turbines with $0^{\circ}$ blade overlap generated the highest power output. Helical turbines were found to generate decreasing power outputs as blade overlap angle increased due to the resultant blade inclination to the inflow. Blade section inclination to the inflow also found to influence power output. Some benefits of helical blade turbines over their straight blade counterparts were established; helical turbine torque oscillation levels and mounting forces were reduced when compared to straight-bladed turbines. For both straight and helical turbines maximum forces levels were found to exceed the average forces by more than $40 \%$, with large cyclical loading forces identified.

Keywords: Vertical Axis Turbine, Helical Bladed, Straight Bladed, Computational Fluid Dynamics, Three Dimensional, Ocean Energy

\section{Highlights:}

- Straight bladed turbines generate more power than helical turbines for same frontal area.

- Helical turbines exhibit reductions in torque oscillation and mounting force levels when compared to straight bladed turbine designs. 


\section{Introduction}

Straight bladed vertical axis turbines, as proposed for tidal power generation, experience significant torque oscillations as a result of changing angles of attack on the blade as they rotate [13]. These oscillations generate alternating loading forces on the turbine structure that can lead to premature failure through fatigue if not adequately accounted for [4,5]. Research using Experimental Fluid Dynamics (EFD) has demonstrated that the use of helical bladed turbines can reduce torque oscillation levels $[4,6,7]$, as the flow does not concurrently stall along the full blade length due to the blade distribution around the rotational axis [8]. However helical blade overlap, $\phi$, shown in Figure 1, may influence power generation due to the inclination of the helical blades to the inflow. To investigate any relationships between these factors two approaches can be utilised: EFD or numerical simulation using methods such as Computational Fluid Dynamics (CFD).

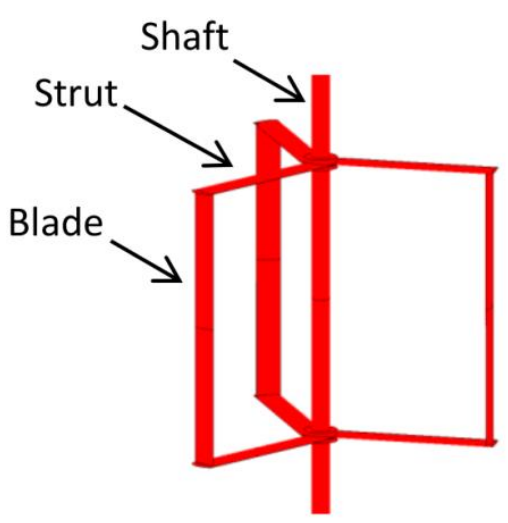

(a)

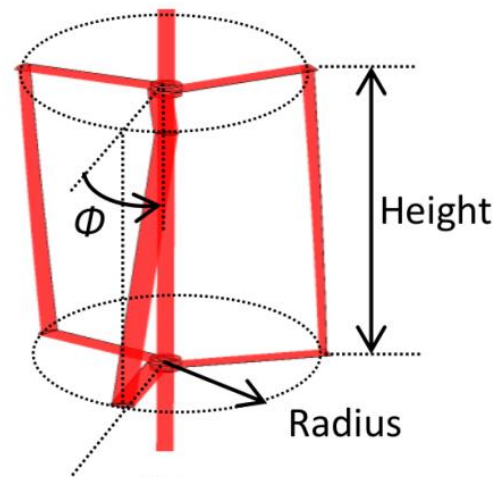

(b)

Figure 1: Straight (a) and helical (b) bladed vertical axis turbines, including the definition of the helical blade overlap angle, $\phi$

Although EFD testing results concur that helical bladed turbines exhibit reduced torque oscillation levels $[4,6,7]$, there is general disagreement about the effects of helicity on power output. Shiono et al. [6] tested a series of straight and helical bladed turbines with NACA633018 blade sections of the same overlap angle but differing turbine spans. They demonstrated that helicity decreased power output, and concluded that it was more appropriate to use straight rather than helical bladed turbines to generate maximise power output. Niblick [7] performed EFD testing on two helical turbines with three and four NACA0018 blades of differing helicity. Results indicated that power output reduced as helicity increased, as the helicity increased total lift and hence torque. However, Gorlov [9] compared the power outputs of a straight and $60^{\circ}$ helical bladed turbine of the same radius and height, determining that the helical turbine demonstrated increased power output over the straight-bladed design, in excess of $50 \%$ at some rotational rates. Gorlov also noted improvements of up to $95 \%$ greater power and $50 \%$ higher speed in comparison with a straight bladed turbine of identical overall dimensions during EFD testing of 20 small $0.09 \mathrm{~m}$ diameter models 
[4]. The reasons that Gorlov found power output to increase with blade overlap yet Shiono et al. and Niblick found power output to decrease are unknown, and were a key driver for this research.

Numerical CFD studies of helical vertical axis turbines are limited as Two Dimensional (2D) models cannot be utilised due to the curved blade geometry, resulting in computationally demanding simulations due to the resultant large mesh element counts associated with Three Dimensional (3D) simulations. Castelli and Benini [10] performed 3D CFD studies on a series of $1.03 \mathrm{~m}$ span single blades with overlap angles of $0^{\circ}, 30^{\circ}, 60^{\circ}, 90^{\circ}$ and $120^{\circ}$. Using the Unsteady ReynoldsAveraged Navier-Stokes (URANS) equations and the $k-\omega$ Shear Stress Transport (SST) turbulence model they found that power output reduced as blade overlap angle increased. Hall [11] simulated the power output of single and four bladed helical turbines and compared results with EFD [7] using the URANS k- $\omega$ SST turbulence model. Power output was obtained at three rotational rates was but was found to over predict the measured results by more than $30 \%$. This simulation error was prescribed to the poor modelling of dynamic stall over the blades by the $k$ - $\omega$ SST turbulence model. Studies of the effects of helicity on power output are limited with no comprehensive examinations found in literature.

The influence of blade helicity on power output, torque oscillations, and mounting loading forces were predicted using time-accurate 3D CFD models to allow the establishment of relationships between turbine blade shape and performance characteristics. To ensure numerical simulation accuracy, validation studies were performed on three turbine models to ensure that the CFD models accurately captured the influence of blade geometry on turbine performance characteristics.

\section{Turbine Geometry}

Eight 3D CFD models were developed to investigate the influence of helical blade overlap and section inclination on turbine performance characteristics. The baseline $0^{\circ}$ (straight-bladed) turbine design was geometrically identical to a previously tested EFD turbine [12] to permit validation of the modelling technique. The turbines were designed with ascending blade overlap angles of $0^{\circ}$ (straight-bladed), $15^{\circ}, 30^{\circ}, 60^{\circ}$ and $120^{\circ}$ as shown in Tables 1 and 2 , allowing the direct characterisation of blade overlap with power output, torque fluctuation levels, and mounting forces. The same profile was used for all blade overlap turbines in this series. However, to investigate the influence of blade section inclination, five $15^{\circ}$ blade overlap models with blade sections inclined by $15^{\circ}, 0^{\circ},+15^{\circ},+30^{\circ}$, and $+45^{\circ}$ from the horizontal rotation plane were also developed as shown in Figure 2. 
Table 1: Turbine Design Parameters

\begin{tabular}{|c|c|c|c|c|}
\hline Turbine & $\begin{array}{c}\text { Blade } \\
\text { overlap }(\phi)\end{array}$ & $\begin{array}{c}\text { Section } \\
\text { inclination }\end{array}$ & 3D view & Overlap view \\
\hline $0^{\circ}$ & $0^{\circ}$ & $0^{\circ}$ & & \\
\hline $15^{\circ}+0^{\circ}$ & $15^{\circ}$ & $0^{\circ}$ & & \\
\hline $15^{\circ}-15^{\circ}$ & $15^{\circ}$ & $-15^{\circ}$ & & \\
\hline $15^{\circ}+15^{\circ}$ & $15^{\circ}$ & $+15^{\circ}$ & & \\
\hline $15^{\circ}+30^{\circ}$ & $15^{\circ}$ & $+30^{\circ}$ & & \\
\hline $15^{\circ}+45^{\circ}$ & $15^{\circ}$ & $+45^{\circ}$ & & \\
\hline $30^{\circ}$ & $30^{\circ}$ & $0^{\circ}$ & & \\
\hline $60^{\circ}$ & $60^{\circ}$ & $0^{\circ}$ & & \\
\hline $120^{\circ}$ & $120^{\circ}$ & $0^{\circ}$ & & \\
\hline
\end{tabular}

Page | 4 
Table 2: Turbine Geometrical Parameters

\begin{tabular}{cccc}
\hline Nomenclature & $0^{\circ}[12]$ & $0^{\circ} \mathrm{A}[12]$ & Lucid [13,14] \\
\hline Number of blades & 3 & 3 & 3 \\
Blade section & NACA634021 & NACA634021 & NACA0020 \\
Blade chord & 0.0653 & 0.0653 & 0.14 \\
Radius & $0.4572 \mathrm{~m}$ & $0.4572 \mathrm{~m}$ & $0.5 \mathrm{~m}$ \\
Blade span & $0.6858 \mathrm{~m}$ & $0.6858 \mathrm{~m}$ & 1.32 \\
Strut section & NACA0012 & Shaped Bar & NACA0012 \\
Strut chord & $0.0653 \mathrm{~m}$ & $0.0467 \mathrm{~m}$ & $0.14 \mathrm{~m}$ \\
Number of struts per blade & 2 & 2 & 2 \\
Shaft diameter & $0.0483 \mathrm{~m}$ & $0.0483 \mathrm{~m}$ & $0.03175 \mathrm{~m}$ \\
\hline
\end{tabular}

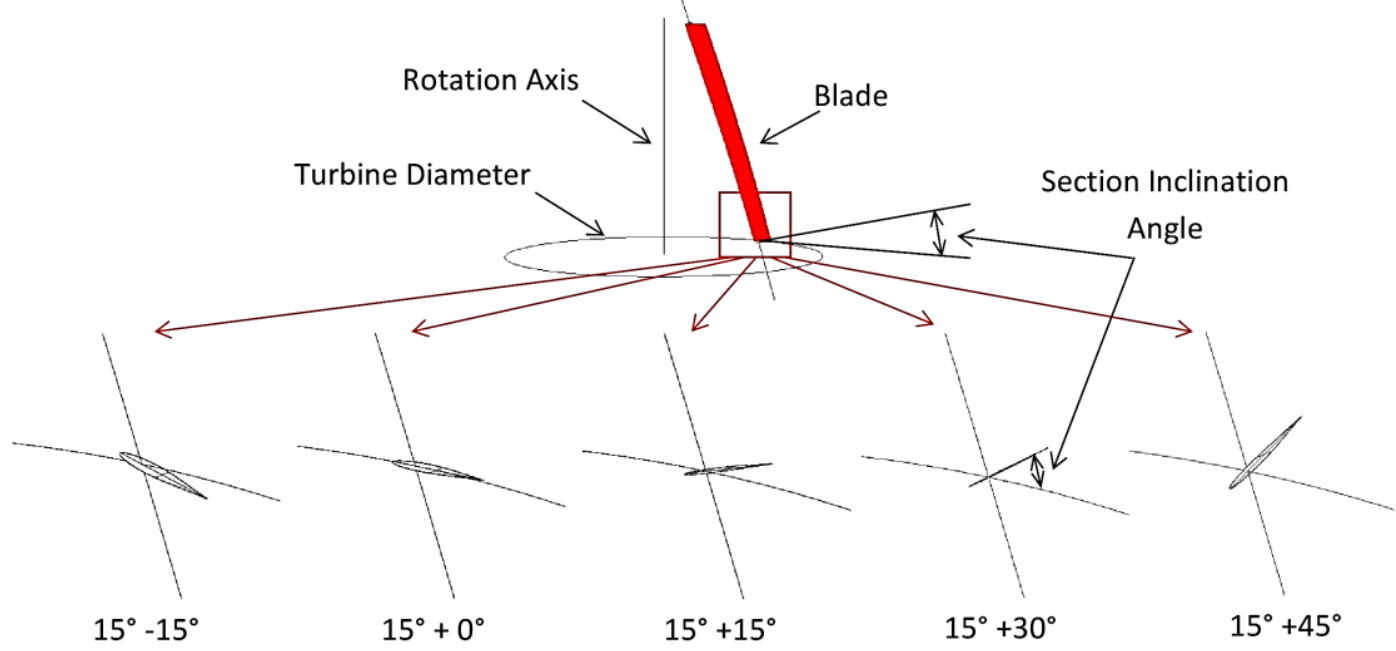

Figure 2: Definition of section inclination angle of the NACA634021 blade secton to the horizontal rotation plane

To ensure the accuracy of the numerical methods utilised, validation studies were performed for two straight and one helical bladed turbines, with all geometrical details shown in Tables 2 and 3 [12-14]. All validation studies were performed at full-scale to ensure that the results were influenced by neither scaling nor Reynolds number effects. The $0^{\circ}$ and $0^{\circ} \mathrm{A}$ turbines differed in strut section and strut location, allowing validation of geometrical changes against EFD results [12]. 
Table 3: Validation Turbine Geometrical Design Parameters [12-14]

\begin{tabular}{|c|c|c|c|c|c|}
\hline Name & $\begin{array}{c}\text { Blade } \\
\text { overlap }\end{array}$ & $\begin{array}{c}\text { Section } \\
\text { inclination }\end{array}$ & 3D view & Overlap view & Strut Connection \\
\hline Lucid & $60^{\circ}$ & $22^{\circ}$ & \\
\hline $\mathbf{0}^{\circ}$ & $0^{\circ}$ & $0^{\circ}$ & \\
\hline $\mathbf{0}^{\circ} \mathrm{A}$ & $0^{\circ}$ & $0^{\circ}$ & & \\
\hline
\end{tabular}

\section{Numerical Simulation Methodology}

Turbine power output, torque fluctuation levels, and mounting loading were simulated using transient time-accurate 3D CFD models using ANSYS CFX [15], which solved the incompressible fully turbulent URANS equations using an element-based finite volume method. Several performance parameters were investigated to enable the quantification of turbine efficiency and operating loading characteristics. Turbine power output was evaluated as the power coefficient, $C_{p}$, given by,

$$
C_{p}=\lambda C_{m}
$$

where tip speed ratio, $\lambda$, was defined as,

$$
\lambda=r \omega / V
$$

where $\omega$ was the turbine rotational rate, $r$ was the turbine radius, and $V$ was the inflow velocity. The turbine torque coefficient, $C_{m}$, was determined as,

$$
C_{m}=\frac{\text { Torque }}{0.5 \rho V^{2} S r}
$$

where $\rho$ was the water density (set to $997 \mathrm{~kg} / \mathrm{m}^{3}$ for all simulations), $S$ was the turbine frontal area, and the Torque generated by the turbine was taken from the respective CFD or EFD results. 
The k- $\omega$ SST turbulence model was utilised due to its ability to accurately model both free stream and boundary layer regions as well as offering improved prediction of flow separation and adverse pressure gradients by the inclusion of transport effects into the formulation of the eddyviscosity [16], with the $k-\omega$ SST CFD turbulence model commonly used for vertical axis turbine simulations [2,10,17-21]. To ensure numerical accuracy and stability, all simulations were performed using a bounded second order upwind biased high order advection scheme along with an unbounded second order backwards Euler transient [15]. Simulations using an first order upwind advection and first order backwards Euler transient scheme resulted in extremerly poor resolution of $C_{p}$. Convergence was deemed achieved when solution residuals reduced to below $10^{-4}$ and reduced by more than three orders of magnitude. Additionally convergence was confirmed by ensuring that the final $C_{p}$ determined was within $5 \%$ of the previous rotations results, required due to the periodic nature of $C_{p}$. An example of $C_{p}$ convergence for the $0^{\circ}$ turbine is shown in Figure 3 , where $C_{p}$ values converged after approximately 3600 time steps, corresponding to 9 rotations. To reduce overall simulations times all simulations were started using previous simulation results if available.

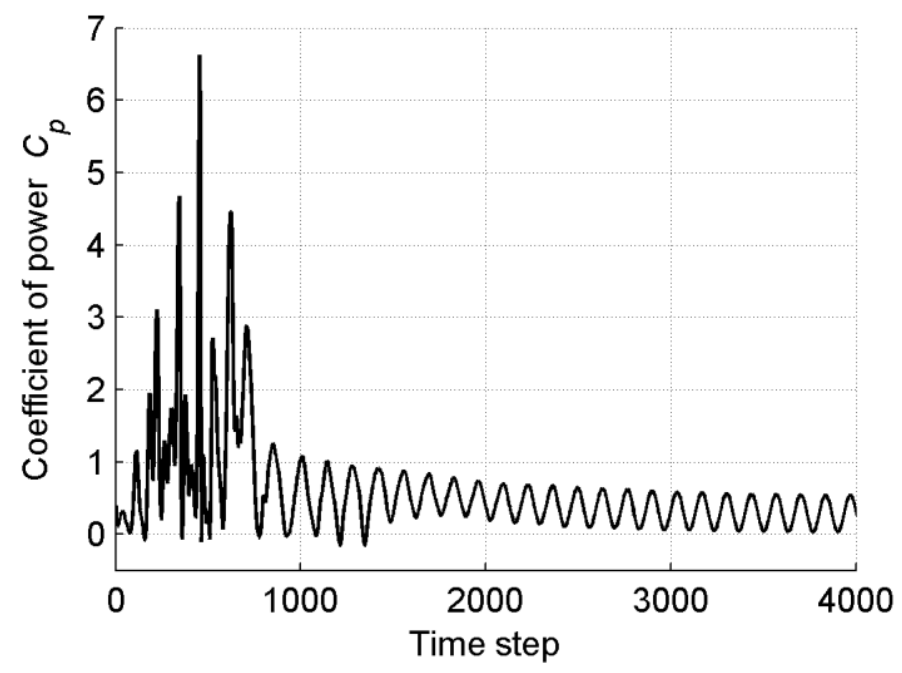

Figure 3: Example of $C_{p}$ convergence for the $0^{\circ}$ turbine at $\lambda=2.75$ at an inflow velocity of 1.5 $\mathrm{ms}^{-1}$

All turbine models were meshed using unstructured tetrahedral elements using ANSYS CFX 13.0 [15] and included all blades, struts, hubs, and shaft. Mesh resolution was set by specifying the mesh size and growth rates to allow for local refinement of mesh zones. Mesh density was varied according to expected flow curvature rates resulting in increased mesh density in regions near the blades, struts, hubs, shaft, and turbine wake region. Mesh density near the leading and trailing edges of the blades and strut sections was increased compared to density in the central sections to capture the expected flow velocity gradients using the ANSYS curvature function [15]. Mesh density was reduced away from the surfaces to minimise computational effort such as on the domain boundary fields. Inflation layers were used on all surfaces to fully resolve the flow boundary. Total boundary layer thickness was estimated as $0.37 c / R e^{\frac{1}{5}}$ with the blade chord $c$ used to determine Reynolds number, Re [22]. The estimated thickness doubled to ensure the boundary layer was 
contained within the prescribed inflation layer region, with a total of 30 layers used to capture the boundary layer flow. Inflation layer mesh growth rates were limited to 1.2, with lower growth rates resulting in excess boundary layer mesh with no beneficial increase in power output simulation accuracy. Boundary layer mesh density independence was evaluated by examining the influence on power output of the average height of the first cell from the turbine walls, known as the nondimensional variable $y+$. The resultant $y+$ values for all 3D models were approximately $y+=0.75$, which aligned well with recommended near wall resolution ranges for the $k-\omega$ SST turbulence model [15]. Simulations using reduced boundary layer inflation density and thus higher $y+$ values resulted in reduced simulation accuracy as the ANSYS-prescribed wall functions [15] were unable to resolve the flow near the walls due to high levels of separation and adverse pressure gradients.

Turbine rotation was simulated by enclosing the turbine in an inner domain as shown in Figure 4 that was rotated using the CFX transient rotor-stator model at the desired $\lambda$ corresponding to the relevant CFD or EFD rotational rates. The interface between the stationary and rotating domains was modelled using a General Grid Interface (GGI) over which flow values were calculated using an intersection algorithm [15]. The GGI interface was placed at 1.5 times turbine diameter from the rotational axis to limit any interpolation errors on power output predictions by increasing clearance between the blades and the interface.

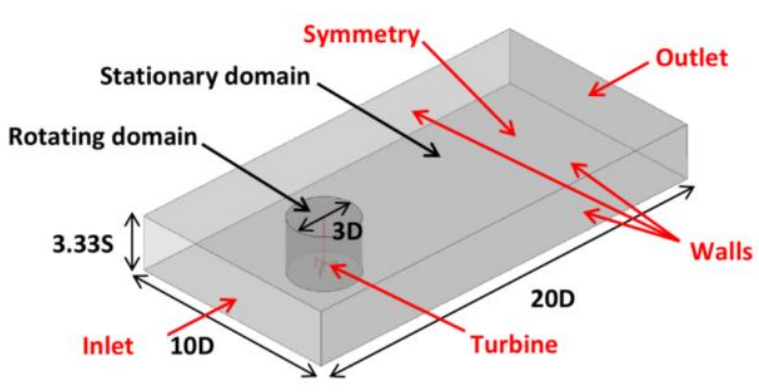

(a)

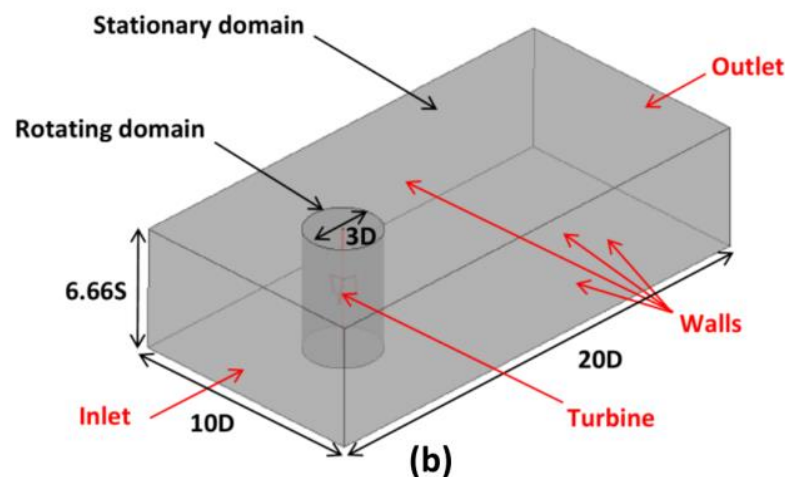

(b)

Figure 4: Domain boundary nomenclature and sizing for (a) symmetrically reduced and (b) full domain. Dimensions in relation to turbine diameter, D, and span, $S$

The computational domains shown in Figure 4 were generated to simulate free stream conditions with all corresponding boundary conditions outlined in Table 4. To ensure that turbines were isolated from any domain wall effects and to allow for full wake development, systematic domain size studies were performed. These studies ensured that the domain walls did not influence $C_{p}$ results, allowing the use of blockage corrected EFD data where available. All turbines were assumed to operate at sufficient depth to minimise any free surface interaction effects. A reduced domain was used for the $0^{\circ}$ and $0^{\circ} \mathrm{A}$ turbines due to symmetry about the horizontal axis as shown in Figure 4. To ensure that this use of domain symmetry did not affect simulation accuracy, equivalent simulations were carried out on full and half domains. The differences in $C_{p}$ for the two domains 
were less than $0.4 \%$, justifying the employment of the half domain thus reducing the overall mesh size by a factor of two.

Table 4: Boundary Conditions for all Turbines

\begin{tabular}{cc}
\hline Boundary & Condition \\
\hline Inlet & Uniform flow: $1.5 \mathrm{~ms}^{-1}$ for Helical Study \\
& $1 \mathrm{~ms}^{-1}$ for Lucid Study \\
Inlet turbulence level & $5 \%$ turbulence \\
Outlet & Pressure: O Pa \\
Walls & Free slip walls \\
Turbine & No slip walls \\
\hline
\end{tabular}

Studies of the influence of factors including mesh density, time step size, $y+$, domain length, width, height, and domain symmetry were conducted. Independence was deemed satisfactory when changes in these parameters resulted in $C_{p}$ differences between successive refinements trending to less than $5 \%$, resulting in a suitable balance between solution accuracy and computational effort. Whilst examples of this method are shown in Figure 5 for the $0^{\circ}$ and $15^{\circ}$ overlap turbines, spatial and temporal independence was determined for all the turbine models with most simulations exhibiting monotonic convergence characteristics. The resultant mesh element counts and time step sizes are outlined in Table 5.
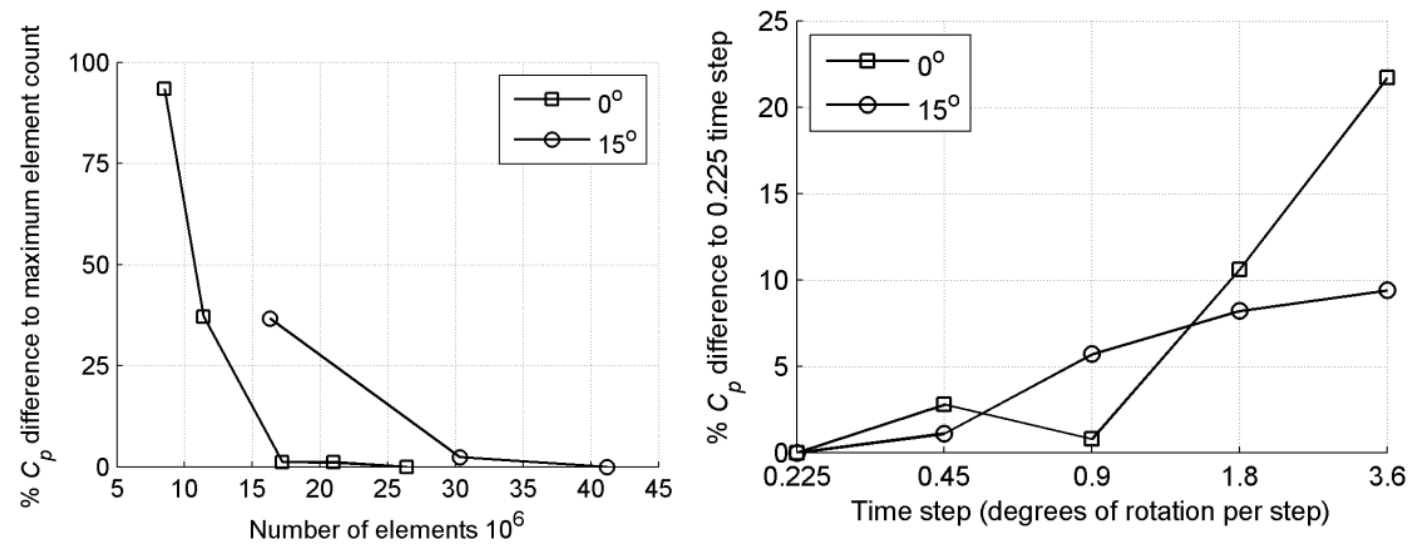

Figure 5: Example of spatial and temporal independence for the $0^{\circ}$ and $15^{\circ}$ blade overlap turbines at $\lambda=2.75$ at an inflow velocity of $1.5 \mathrm{~ms}^{-1}$

Table 5: Spatial and Temporal Independence Results

\begin{tabular}{llllllllllll}
\hline Turbine & $0^{\circ} \mathrm{A}$ & $0^{\circ} \mathrm{B}$ & Lucid & $15-15^{\circ}$ & $15^{\circ}+0^{\circ}$ & $15^{\circ}+15^{\circ}$ & $15^{\circ}+30^{\circ}$ & $15^{\circ}+45^{\circ}$ & $30^{\circ}$ & $60^{\circ}$ & $120^{\circ}$ \\
Mesh size $10^{6}$ & 17.2 & 17.3 & 37.2 & 31.9 & 30.3 & 30.9 & 30.0 & 29.8 & 31.7 & 37.0 & 54.0 \\
Rotation / time step & 0.9 & 0.9 & 0.9 & 0.45 & 0.45 & 0.45 & 0.45 & 0.45 & 0.45 & 0.45 & 0.45 \\
\hline
\end{tabular}




\section{Validation Studies}

Validation studies of the Lucid model were conducted against EFD testing available from literature of a geometrically identical turbine at the University of New Hampshire Tow and Wave Tank at the Chase Ocean Engineering Laboratory, a $36.6 \mathrm{~m}$ long, by $3.66 \mathrm{~m}$ wide and $2.13 \mathrm{~m}$ deep testing tank $[13,14]$. Measurements of torque generated at inflow velocities ranging from $0.6 \mathrm{~ms}^{-1}$ to $1.3 \mathrm{~ms}^{-1}$ were obtained at varying rotational rates using a torque transducer and a hydraulic disk brake arrangement. Comparisons of CFD and EFD $C_{p}-\lambda$ performance curves for the Lucid turbine are shown in Figure 6. There was good agreement between the CFD and EFD results, with both the shape of the $C_{p}-\lambda$ curve and maximum $C_{p}$ magnitudes correlating well, with for example the CFD $C_{p}=0.236$ within $4.8 \%$ of the EFD of $C_{p}=0.248$ at $\lambda=2$. The $C_{p}-\lambda$ curve was shifted minimally to lower $C_{p}$ values at $\lambda$ increased. The under prediction of $C_{p}$ may result from over prediction of blade and strut drag as a consequence of the use of a fully turbulent CFD model, as they often overestimate skin friction and hence drag particularly at low angles of attack that occur at high $\lambda$ [23]. Fully turbulent model will also not capture any laminar to turbulent transition effects which may occur due to flow Reynolds numbers which were less than 500,000. Given the replication of the shape of the $C_{p}-\lambda$ curve and the accurate prediction of maximum $C_{p}$ the additional computational expense [15] of laminar to turbulence transitional models was not deemed necessary.

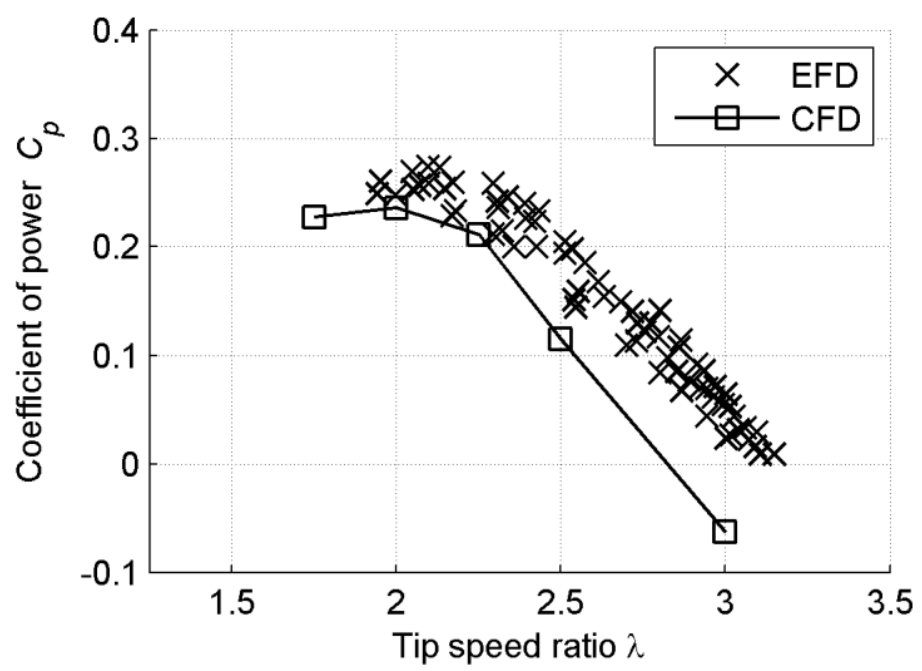

Figure 6: Comparison of CFD and EFD $C_{p}-\lambda$ curves for Lucid turbine at an inflow velocity of 1 $\mathrm{ms}^{-1}[13,14]$.

Validation of the $0^{\circ}$ and $0^{\circ} \mathrm{A}$ CFD models shown in Table 3 was performed against EFD results available in the literature for two geometrically identical turbines conducted at the University of British Columbia's towing tank, a $60.1 \mathrm{~m}$ long, $3.7 \mathrm{~m}$ wide and $2.4 \mathrm{~m}$ deep facility [12]. Using a torque sensor and rotation rate encoder, power output was measured for varying rotational rates from $\lambda=1.5$ to $\lambda=3.5$ at inflow velocities of 1.5 to $2 \mathrm{~ms}^{-1}$. Figure 7 shows the comparisons of CFD and EFD 
$C_{p}-\lambda$ curves for the $0^{\circ}$ and $0^{\circ} \mathrm{A}$ turbines shown in Table 3 at $1.5 \mathrm{~ms}^{-1}$. At low $\lambda$ (less than 2.5) good agreement was found between the CFD and EFD results for both turbines, with differences in $C_{p}$ between CFD and EFD results for turbine $0^{\circ}$ of $17 \%$ and $0.8 \%$ at $\lambda=1.5$ and $\lambda=2.5$ respectively. Turbine $0^{\circ} \mathrm{A}$ prediction accuracy at low $\lambda$ was similar with differences in $C_{p}$ prediction of $14.4 \%$, and $1.7 \%$ at $\lambda=2$ and 2.25 respectively. However, $C_{p}$ prediction accuracy reduced as $\lambda$ increased past the location of maximum $C_{p}$ with CFD $C_{p}$ values shifted lower. The authors suggest that the reasons for increased error at high $\lambda$ are threefold: lack of blockage corrections, the use of a fully turbulent CFD model, and possible experimental inconsistencies at higher rotational rates. The EFD results did not account for the tank blockage of $8 \%$ by the turbine, which may reduce $C_{p}$ magnitudes and shift the $C_{p}-\lambda$ curve to a lower $\lambda$ values as shown in Lucid EFD, where $C_{p}$ was reduced on average by $25 \%[13,14]$. The under prediction of $C_{p}$ at high $\lambda$ may also result from over prediction of blade and strut drag as a result of the use of a fully turbulent CFD model, which often overestimate skin friction and hence drag [23]. Fully turbulent models will also not capture any laminar to turbulent transition effects which may occur due to the low blade and strut Reynolds numbers of less than 500,000. Additionally the $C_{p}-\lambda$ curve for the $0^{\circ}$ turbine appears to plateau whereas all other EFD from the same testing regime [12] reveal rapid decreases in $C_{p}$ at high $\lambda$, suggesting possible experimental error at $\lambda=3.5$.

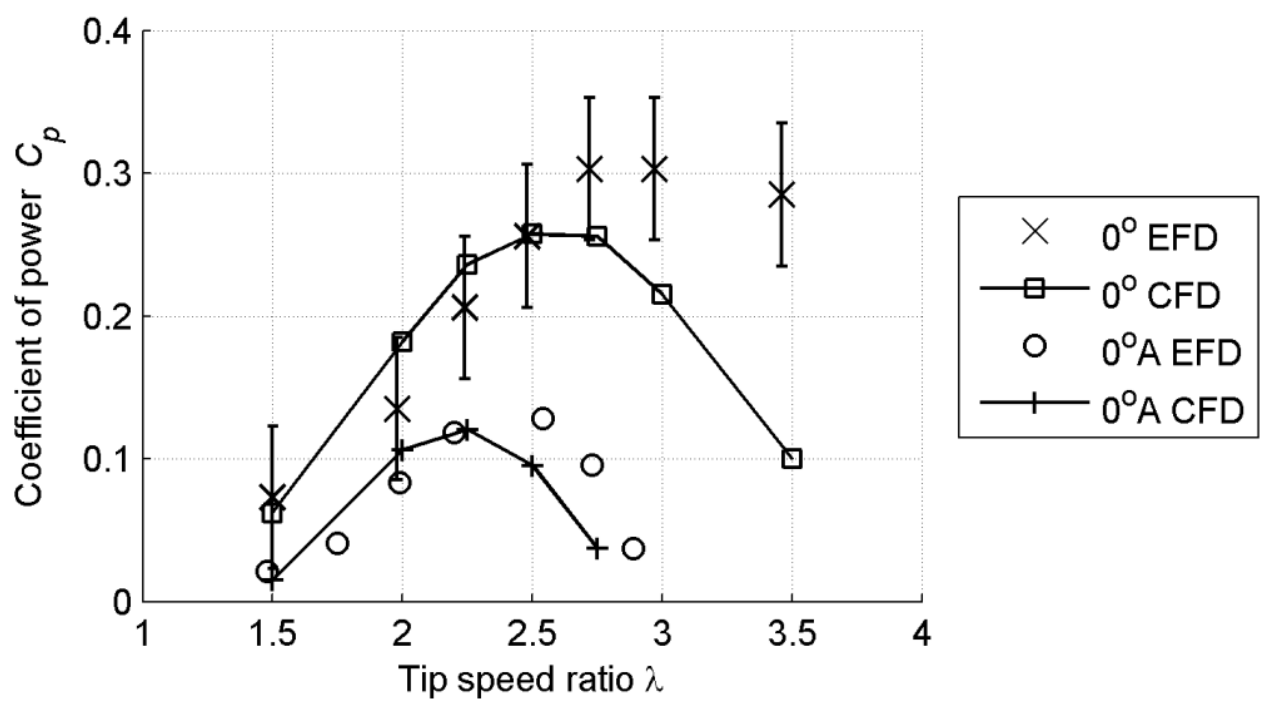

Figure 7: Comparison of CFD and EFD $C_{p}-\lambda$ curves for the $0^{\circ}$ and $0^{\circ} \mathrm{A}$ turbines at an inflow velocity of $1.5 \mathrm{~ms}^{-1}$. Error bars only reported for Turbine $0^{\circ}$ [12]

The CFD models accurately captured the effect of geometrical changes on maximum $C_{p}$ with results correlating to within $4.8 \%, 14.3 \%$ and $6.3 \%$ of the EFD results for the Lucid, $0^{\circ}$ and $0^{\circ} \mathrm{A}$ turbines respectively. This prediction accuracy is higher than previous CFD predictions available in the literature, which exhibited maximum $C_{p}$ prediction errors of more than $45 \%[2,11,24-27]$.

\subsection{Computational Requirements}


Total simulation time was found to vary significantly as mesh element counts increased with blade overlap angle as shown in Table 5. Simulations for one revolution of the $0^{\circ}$ overlap turbine model took 24 hours on an 18 core cluster comprising of Intel Core 2 Quad Q9300 processors with $2 \mathrm{~GB}$ memory per core, however simulations for the $120^{\circ}$ overlap turbine took in excess of 72 hours for one revolution on 50 cores of the same cluster as a result of the increase in mesh element counts. Due to the continual increases of computing power available to CFD users, the use of full 3D CFD simulation models for vertical axis turbines is now possible without the need for unrealistic computational resources or time requirements.

\section{Results and Discussion}

The influence of overlap angle and section inclination angle on power output, torque oscillation levels and mounting forces was determined using 3D CFD models at an inflow velocity of $1.5 \mathrm{~ms}^{-1}$. The 3D CFD models utilised varied in blade overlap angles from $0^{\circ}$ (straight-bladed) to $120^{\circ}$ and section inclination angles from $-15^{\circ}$ to $60^{\circ}$ to determine any relationships between turbine geometrical design and performance.

\subsection{Influence of Helicity on Power Output}

Figure 8 shows comparisons of CFD simulation results of power output for varying blade overlap angles. Power output was found to be directly proportional to blade overlap. The highest $C_{p}=0.258$ was found for the $0^{\circ}$ blade overlap turbine. As helicity increased, maximum $C_{p}$ reduced eventually becoming negative at all $\lambda$ for the $120^{\circ}$ overlap turbine. These results signify that turbines with $0^{\circ}$ blade overlap, known as straight-bladed turbines, will develop the highest $C_{p}$. As blade overlap increased, the $C_{p}-\lambda$ curves shifted to lower $C_{p}$ values for all $\lambda$ as the reductions in the blade inclination angle to the inflow increased the magnitude of spanwise flow over the blades. The $C_{p}-\lambda$ coefficient curves for all helical turbines were shifted to higher $\lambda$ by $\lambda=0.25$ when compared to the $0^{\circ}$ overlap turbine as the spanwise flow deformation reduced the effective blade chord and thus turbine solidity. 


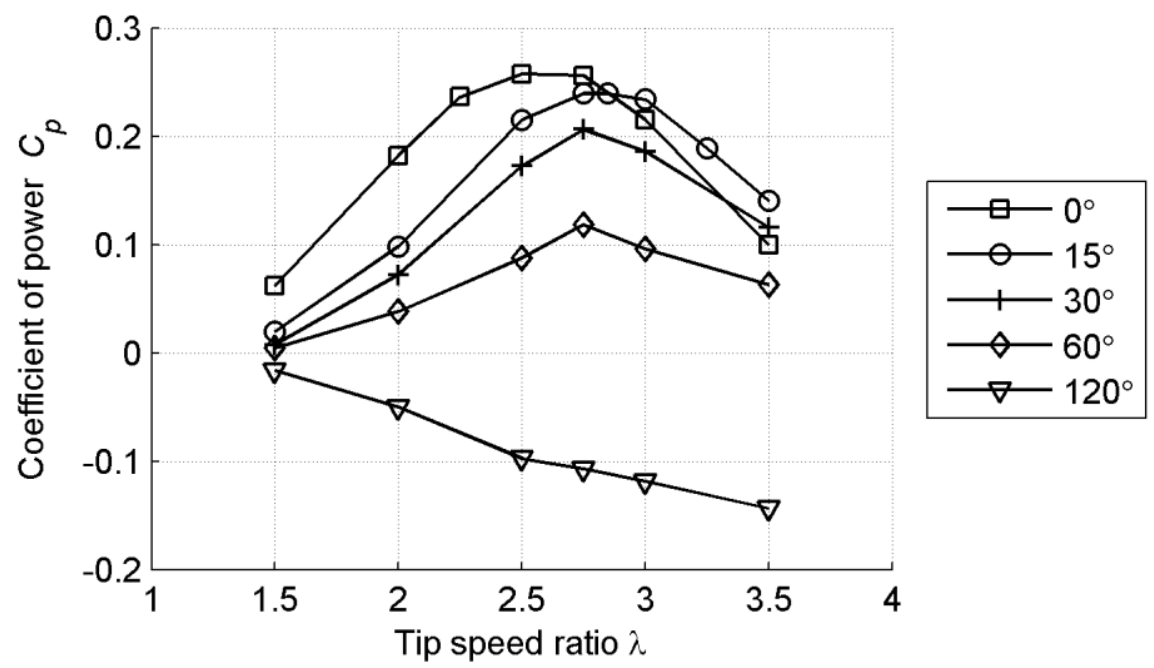

Figure 8: Comparison of CFD $C_{p}-\lambda$ curves for blade overlap angles from $0^{\circ}$ to $120^{\circ}$ at an inflow velocity of $1.5 \mathrm{~ms}^{-1}$

Differences in flow deformation are shown in Figure 9 for the $0^{\circ}, 60^{\circ}$ and $120^{\circ}$ overlap turbines. Flow over the $0^{\circ}$ overlap turbine was perpendicular to the blade section due to the blade inclination angle of $90^{\circ}$, resulting in optimal hydrodynamic section alignment and thus maximum power output. However, the flow over the blades of the $60^{\circ}$ overlap turbine was deformed in a spanwise direction, reducing the hydrodynamic efficiency of the NACA sections. Correspondingly at $120^{\circ}$ overlap the blade sections were poorly aligned with the flow, resulting in negative power outputs for all $\lambda$. This flow deformation was found by Castelli and Benini [10] who also found a corresponding increase in $C_{p}$ as helicity reduced.

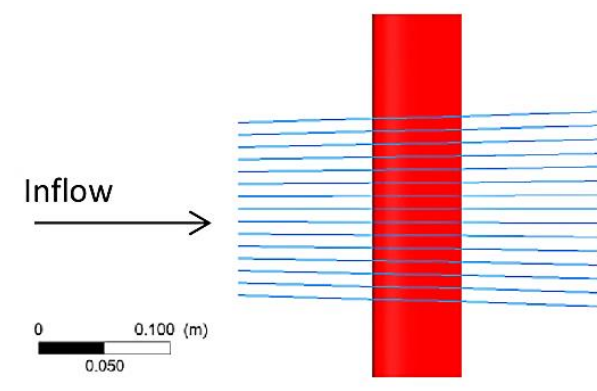

$0^{\circ}$

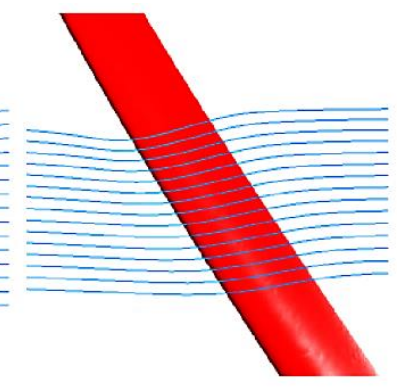

$60^{\circ}$

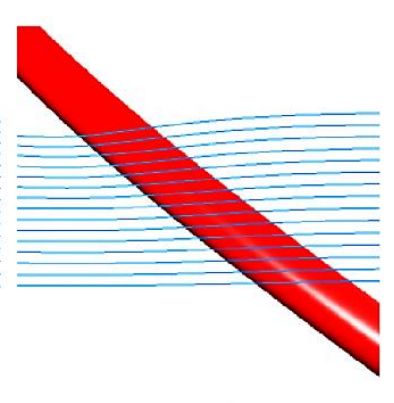

$120^{\circ}$

Figure 9: Comparison of inclination of flow for $0^{\circ}, 60^{\circ}$, and $120^{\circ}$ overlap angle turbines at an inflow velocity of $1.5 \mathrm{~ms}^{-1}, \lambda=2.75$

The derived relationship between helicity and $C_{p}$ is supported by EFD and CFD research from literature where $C_{p}$ was demonstrated to increase as helicity reduced $[6,7,10]$. However, Gorlov 
found during EFD that helical turbines demonstrated $C_{p}$ increases of up to $95 \%$ when compared to straight bladed turbines $[4,9]$. The majority of the published EFD and CFD works however agree that increased helicity results in reduced power output, with straight-bladed turbines generating the highest $C_{p}$ for any given turbine frontal area.

Comparisons of helicity are shown in Figure 10 for the $60^{\circ}$ and $0^{\circ}$ overlap angle turbines. Large levels of flow disruption over the $60^{\circ}$ overlap turbines blades can be seen, which occurred as a result of the spanwise flow caused by the inclination of the turbines blades. This spanwise flow may reduce hydrodynamic performance as the shed vortices traverse down the helical blades. In comparison significant reductions in flow disruption over the blade and strut sections of the $0^{\circ}$ overlap turbine are shown when compared to the $60^{\circ}$ overlap turbine. Differences in tip vortex magnitudes can also be that were generated by differences in pressure variations over the lifting blade surfaces between the two designs.
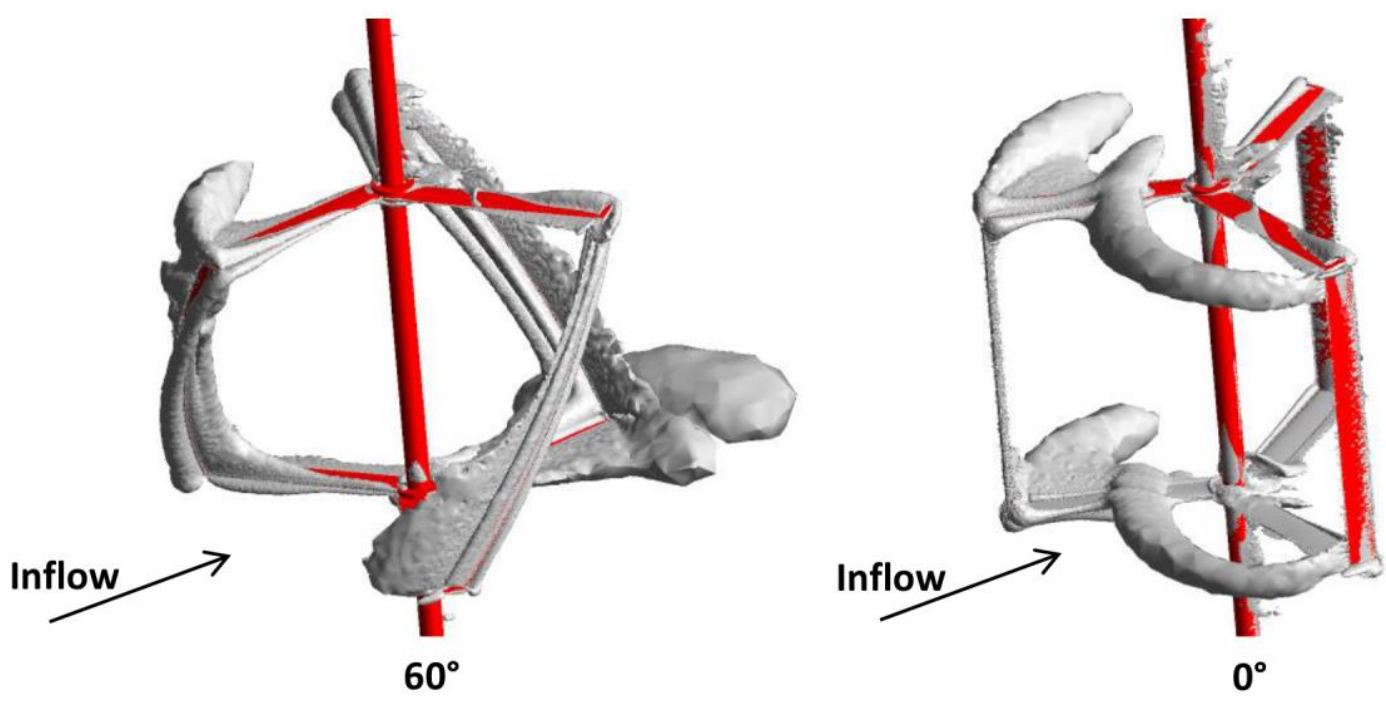

Figure 10: Vortex shedding comparisons between $60^{\circ}$ and $0^{\circ}$ overlap angle turbines, helicity of $16 \mathrm{~ms}^{-2}$ at an inflow velocity of $1.5 \mathrm{~ms}^{-1}$ at $\lambda=2.75$. Vorticity of $16 \mathrm{~ms}^{-2}$

\subsection{Influence of Blade Section Inclination on Power Output}

To examine the influence of blade section inclination, $(\gamma)$, CFD simulations were performed for five turbines with differing section inclination angles as shown in Figure 11. For section inclination angles of $0^{\circ},+15^{\circ}$, and $+30^{\circ}$ minimal changes in $C_{p}$ were found as the hydrodynamic profile of the blade section perpendicular to the flow did not vary significantly. However the $+45^{\circ}$ and $-15^{\circ}$ blade sections were at increasingly tangential angles to the flow reducing their efficiency. 
These results indicate that blade section inclination is not critical for helical vertical axis turbines as long as blade sections are approximately perpendicular to the leading edge.

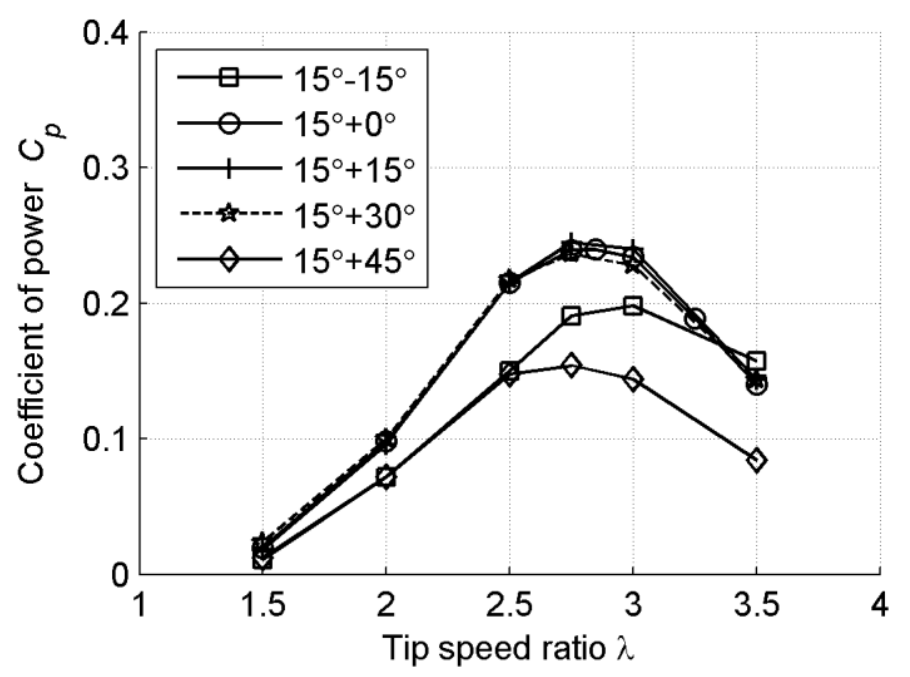

Figure 11: Section inclination effects on the $C_{p}-\lambda$ curves of the $15^{\circ}$ overlap angle turbines with section inclination angles of $0^{\circ},+15^{\circ},+30^{\circ},+45^{\circ}$ and $-15^{\circ}$ at an inflow velocity of $1.5 \mathrm{~ms}^{-1}$

\subsection{Influence of Helicity on Torque Oscillation Levels}

Straight bladed vertical axis turbines experience significant cyclic torque oscillations as a result of variations in blade angles of attack over each revolution [1-3]. These oscillations generate alternating loading forces on the turbine structure that can lead to premature failure through fatigue $[4,5]$. Helical turbines have been reduce levels of toque oscillations due to their blade distribution around the rotational axis [4,6-9]. This distribution ensures that the flow does not stall along the full blade length simultaneously, reducing peaks in tangential force levels and thus moment coefficients. An example of this effect is shown in Figure 12. Three distinct peaks in torque coefficients for each turbine occur as each of the three blades generates peaks in tangential force in the upstream section of the turbine [1]. However, peak helical torque coefficients are reduced by $57.3 \%$ for the $60^{\circ}$ overlap turbine in comparison to the $0^{\circ}$ overlap turbine as a result of the helical blade distribution. Visually the effect of this distribution is shown in Figure 13. The flow angle of attack over the $60^{\circ}$ overlap turbine varies with blade span as a result of the blade distribution, reducing peak tangential forces and thus moment coefficients. In contrast since the flow angle of attack of the $0^{\circ}$ overlap turbine does not vary with blade span, it generates large instantaneous peaks in tangential force and thus moment coefficient peaks. 


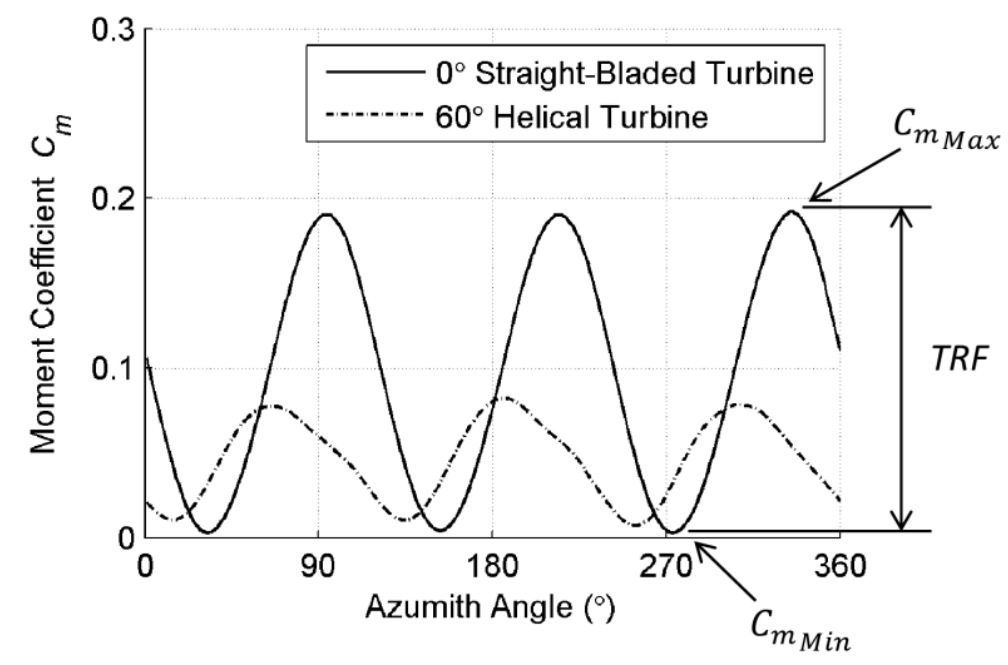

Figure 12: Variations in $C_{m}$ for one revolution for the $0^{\circ}$ and $60^{\circ}$ overlap angle turbines at an inflow velocity of $1.5 \mathrm{~ms}^{-1}$ at $\lambda=2.75$.

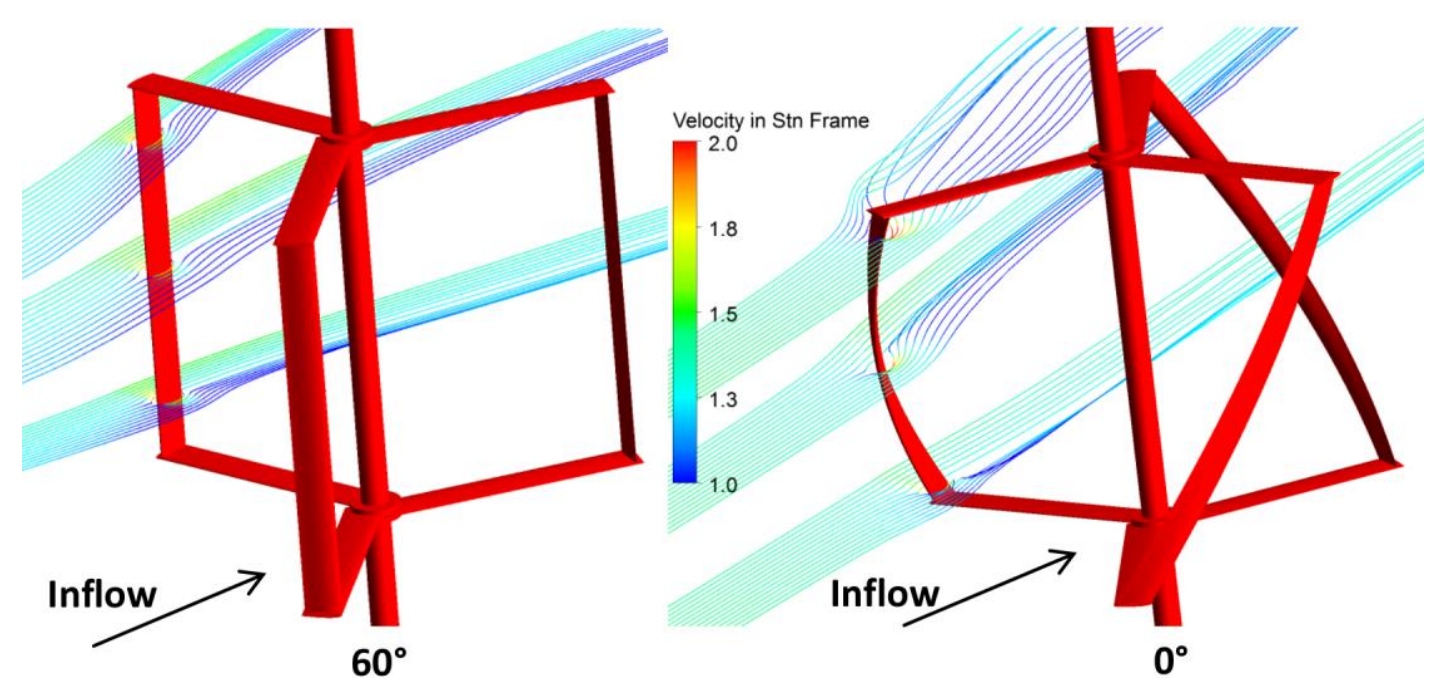

Figure 13: Angle of attack variations with span for $60^{\circ}$ and $0^{\circ}$ overlap angle turbines at an inflow velocity of $1.5 \mathrm{~ms}^{-1}$ at $\lambda=2.75$

To quantify relationships between blade overlap angle and torque oscillation levels, a series of turbines with blade overlaps angles ranging from $0^{\circ}$ to $120^{\circ}$ were simulated. Various methods for quantifying torque fluctuations have previously been used [6,28-30]; in this work torque oscillations were quantified as Torque Ripple Factor (TRF) defined as,

$$
T R F=C_{m_{\text {Max }}}-C_{m_{\text {Min }}}
$$


where $C_{m_{\text {Max }}}$ and $C_{m_{\text {Min }}}$ were the maximum and minimum moment coefficients as illustrated in Figure 12 for the $0^{\circ}$ overlap turbine at $\lambda=2.75$. This formulation allows for easy comparison of the range of torque variations experienced and is similar to that used by Winchester and Quayle [30] and Shiono et al. [6].

Comparison of TRFs are shown in Figure 14 for blade overlap angles of $0^{\circ}, 15^{\circ}, 30^{\circ}, 60^{\circ}$, and $120^{\circ}$. All TRF- $\lambda$ curves prescribe the same form with locations of peak TRF found around the $\lambda$ location of maximum $C_{p}$, reflecting the large variations of tangential forces found at these $\lambda$. Significant reductions of up to $71.7 \%$ in TRF levels at $\lambda=2$ were found when comparing the $0^{\circ}$ and $120^{\circ}$ overlap turbines as the overlap reduces peaks in tangential forces. These results are supported by EFD of helical turbines in literature [4,6-9] where TRF levels was found to be significantly reduced when compared to straight bladed designs. Maximum $C_{p}$ and TRF levels were found to decrease at comparable rates with increasing helicity. Thus, if reductions in TRF are desired, helicity could be increased, although this will also reduce the maximum $C_{p}$.

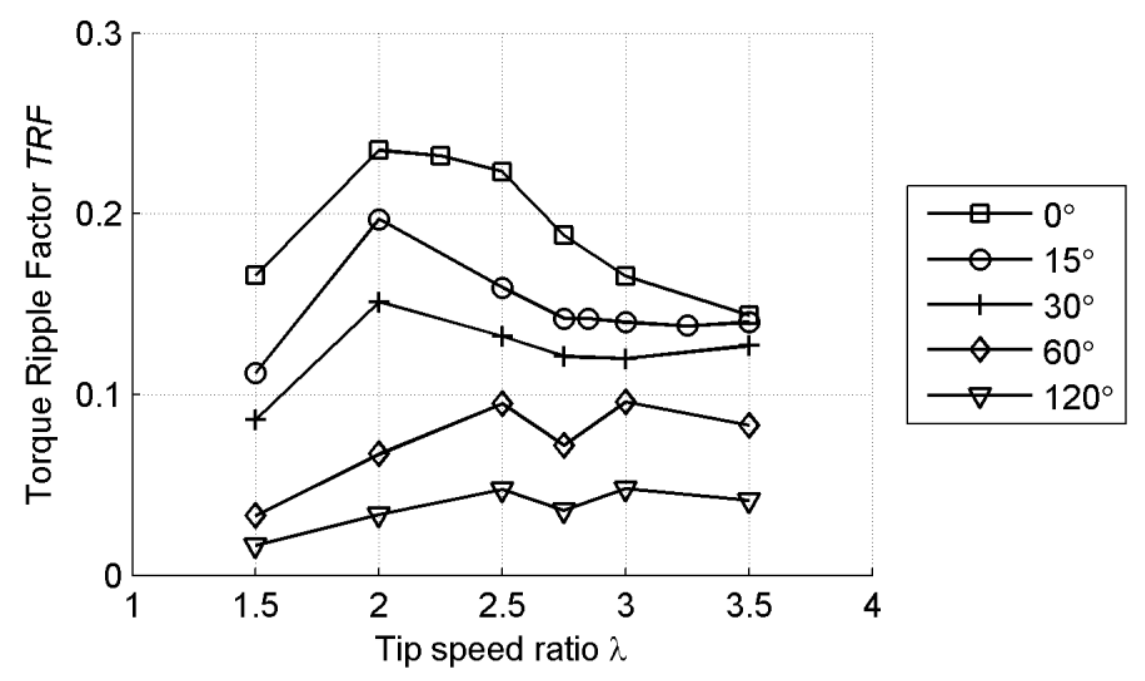

Figure 14: Comparisons of TRF- $\lambda$ for varying overlap angles turbines from $0^{\circ}$ to $120^{\circ}$ at an inflow velocity of $1.5 \mathrm{~ms}^{-1}$

The effects of blade section inclination angle on TRF are shown in Figure 15. In a similar manner to Figure 14, all curves followed a similar TRF- $\lambda$ shape, with the peak located around the $\lambda$ for maximum $C_{p}$, reflecting the large variations of tangential forces found at these $\lambda$. The $15^{\circ}+0^{\circ}$, $15^{\circ}+15^{\circ}$, and $15^{\circ}+30^{\circ}$ section inclination turbines exhibit similar TRF magnitudes as the blades were approximately aligned with the inflow resulting in similar power output magnitudes. However, the $15^{\circ}-15^{\circ}$ and $15^{\circ}+45^{\circ}$ section inclination turbines exhibited reduced TRF as the inclination of the blade sections resulted in reductions in the magnitudes of the alternating forces on the blades. Although beneficial, these reductions in TRF were accompanied with reductions in power output. 


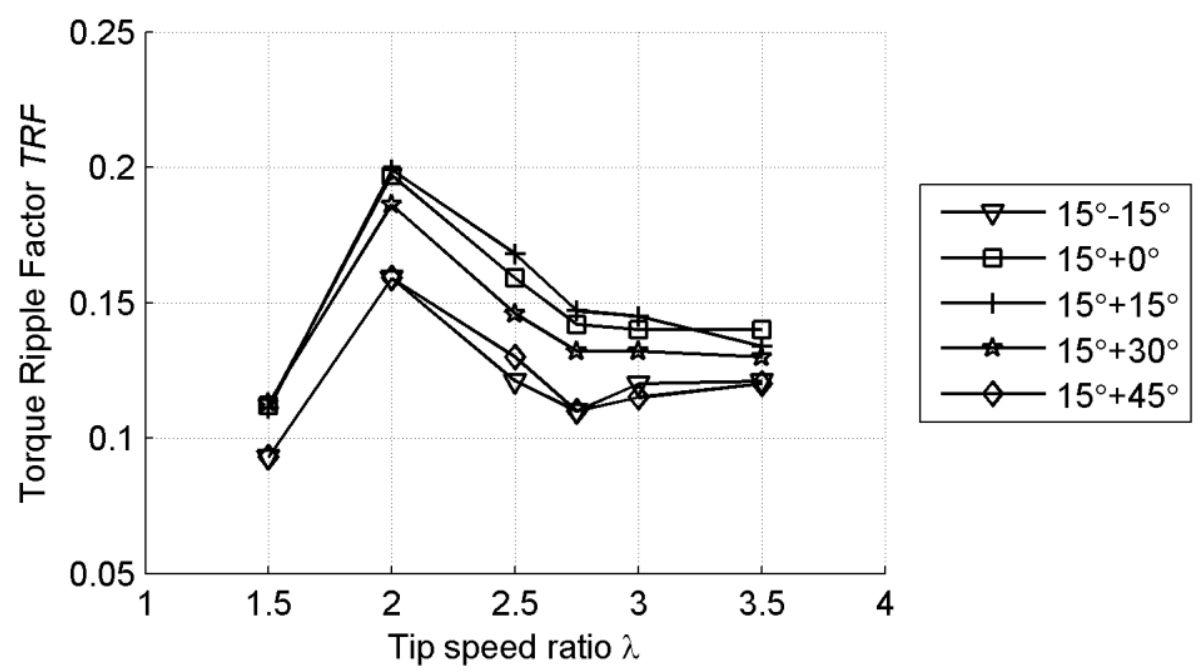

Figure 15: Comparisons of TRF- $\lambda$ for $15^{\circ}$ overlap angle helical turbines from $-15^{\circ}$ to $45^{\circ}$ section inclination angles at an inflow velocity of $1.5 \mathrm{~ms}^{-1}$

\subsection{Influence of Helicity on Turbine Mounting Forces}

Inline, lateral, and vertical forces shown in Figure 16 were determined for turbines with blade overlap angles of $0^{\circ}$ and $15^{\circ}$, as increasing overlap above $15^{\circ}$ resulted in significant reductions in $C_{p}$, as shown in Figure 8. Inline, lateral, vertical and maximum forces were non-dimensionalised by $\frac{1}{2} \rho V^{2} S$ to form the force coefficients $C_{F X}, C_{F Y}, C_{F Z}$ and $C_{F M a x}$ respectively. To ensure CFD simulation accuracy, validation studies were performed against measurements of inline drag obtained from EFD studies available within the literature for the $0^{\circ}$ and Lucid turbines [12-14].

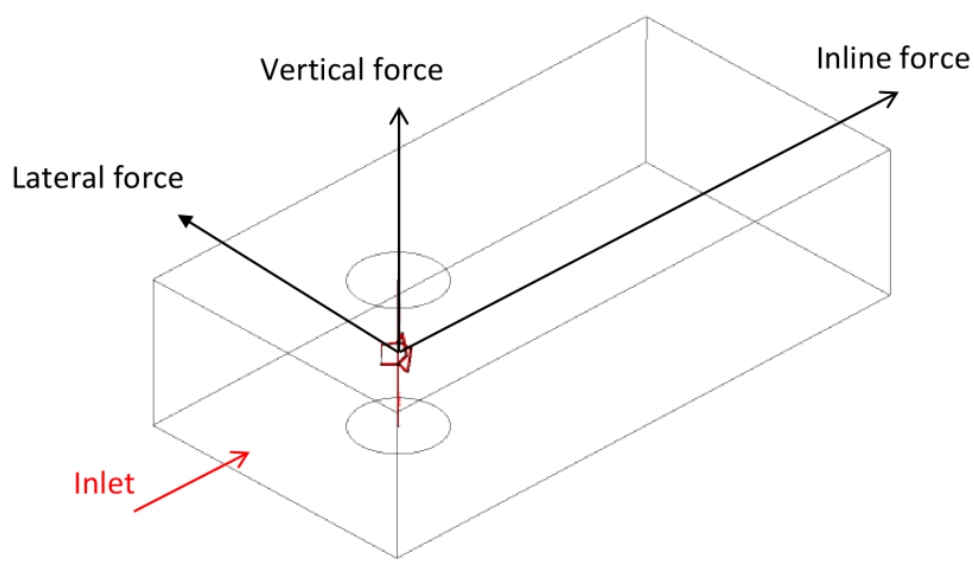

Figure 16: Definitions of lateral, inline, and vertical force vectors for the 3D CFD domains 
Comparisons of average CFD and EFD [12] inline force coefficients $\left(C_{F X}\right)$ for the $0^{\circ}$ overlap turbine are shown in Figure 17. Reasonable agreement between CFD and EFD was found across most $\lambda$ with differences of $8.2 \%$ and $2.5 \%$ at $\lambda=2$ and $\lambda=2.5$ respectively. Reductions in the slope of the CFD curve when compared to EFD may be due to blockage effects which were not accounted for in the CFD studies. Additionally the EFD results do not closely follow any trend with possible experimental error in $C_{F X}$ results at $\lambda=2.25$. The inline force magnitude increased with $\lambda$ due to increased flow turbulence levels over the struts, which increased strut drag and thus the resistive torque generated [17-18]. Increases in inline drag force also occurred as the turbine acts more like a solid body at high $\lambda$ rates [14]. Inline force coefficients were also derived for the Lucid turbine as shown in Figure 17 and compared against EFD results [13-14]. Good agreement between CFD and EFD was found, with all CFD results falling within the reported error bars. Inline force coefficients were approximately constant with $\lambda$ showing similarities with the $0^{\circ}$ overlap turbine in Figure 17, where the inline force coefficients appear to plateau at high $\lambda$ values.

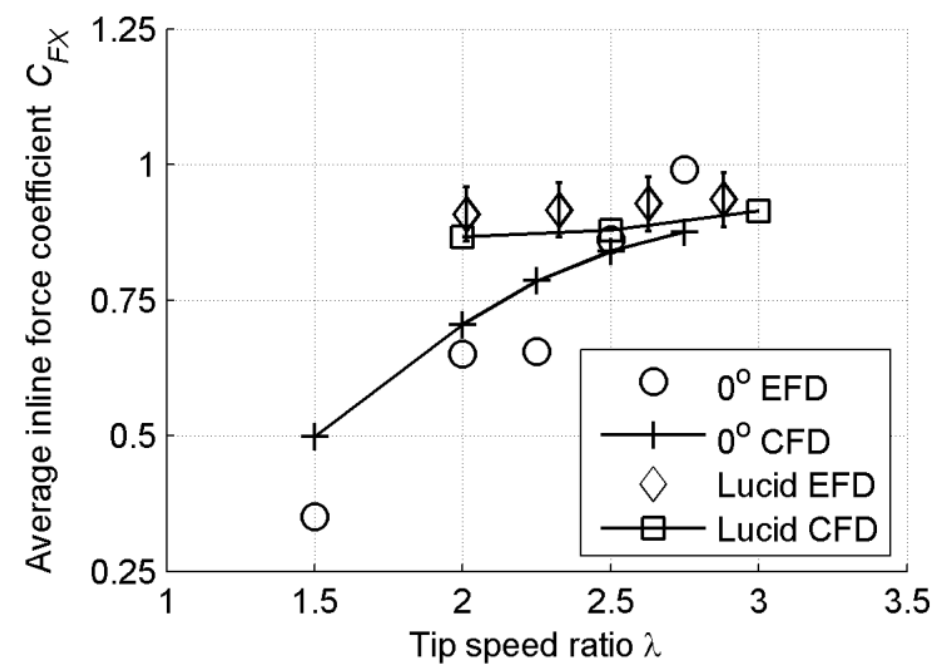

Figure 17: Comparison of average CFD and EFD inline force coefficient, $C_{F X}$, for the $0^{\circ}$ blade overlap [12] and Lucid $[13,14]$ turbine at an inflow velocity of $1.5 \mathrm{~ms}^{-1}$. Lucid error bars reported in EFD [14], no error bars reported in EFD for $0^{\circ}$ blade overlap turbine [12]

Simulation results for all force coefficients are shown in Figure 18 for the $0^{\circ}$ and $15^{\circ}$ overlap turbines. The average lateral forces, $C_{F Y}$, for both turbines remained relatively constant across $\lambda$ and were approximately $75 \%$ lower than inline force coefficients, $C_{F X}$. Average $C_{F X}$ for both turbines rose then appeared to plateau around the $\lambda$ location where maximum $C_{p}$ was found as shown in Figure 8 as the turbines act more like solid bodies at high $\lambda$ rates [14]. Reductions in $C_{F X}$ for the $15^{\circ}$ blade overlap turbine of approximately $20 \%$ were found when compared to the $0^{\circ}$ overlap turbine, as the flow in the downstream direction was not impacting on the full $0^{\circ}$ blade overlap turbine rectangular blade area but rather on a reduced frontal blade area caused by the helicity of the blades. This inline surface area effect is reduced as $\lambda$ increases as the turbine blades act more like a solid body with results converging for both turbines [14]. Vertical forces, $C_{F Z}$, were also calculated for the $15^{\circ}$ overlap turbine as shown in Figure 18, resulting from the spanwise flow deformation 
illustrated in Figure 9. These can lead to axial loadings on shaft bearings however the force magnitudes were small compared with $C_{F X}$ and $C_{F Y}$. Conversely, $0^{\circ}$ overlap turbines in uniform flow exhibit no vertical forces due to their horizontal symmetry. Predicted maximum mounting force coefficients, $C_{F \text { Max }}$, for the $0^{\circ}$ and $15^{\circ}$ overlap angle turbines were found to be up to $40 \%$ higher than the average forces due to TRF (Eqn. 4), with the average loading forces slowly plateauing above $\lambda=3$ due to reductions in shaft drag and changes in blockage as $\lambda$ increased. The helical distribution of the blades of the $15^{\circ}$ blade overlap angle turbine around the rotational axis resulted in reductions of $C_{F M a x}$ when compared to the $0^{\circ}$ overlap turbine; however as $\lambda$ increases the results appear to converge due to blockage effects at high $\lambda$.

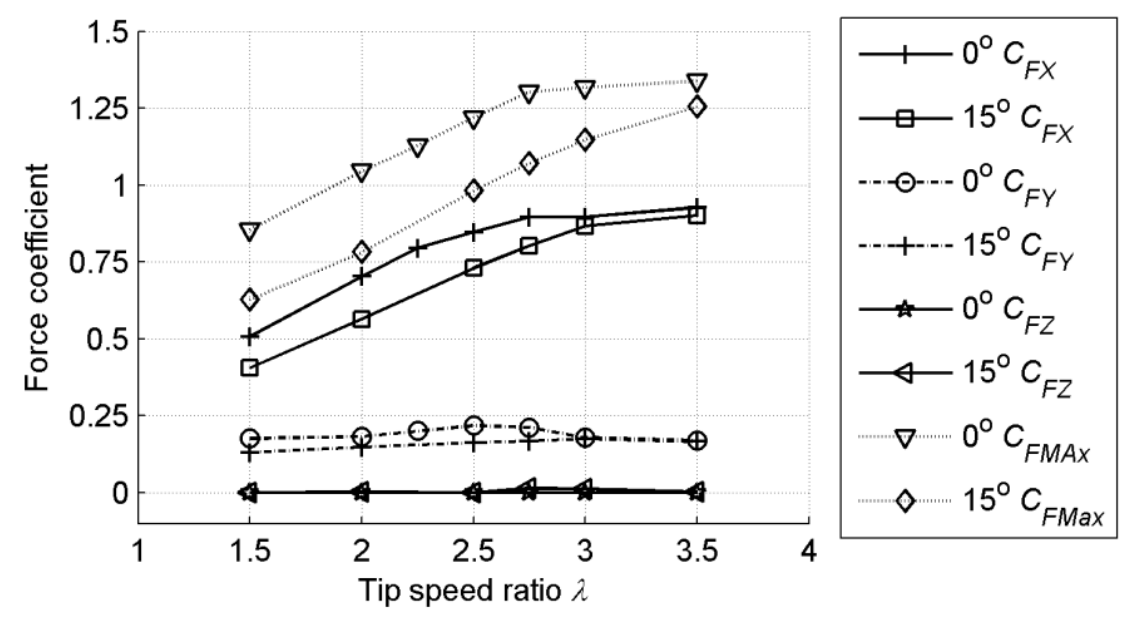

Figure 18: Comparison of average inline, $C_{F X}$, lateral, $C_{F Y}$, vertical, $C_{F Z}$, and maximum, $C_{\text {FMax }}$ force coefficients for $0^{\circ}$ and $15^{\circ}$ overlap angle helical turbines at $1.5 \mathrm{~ms}^{-1}$

The fluctuating forces in the inline and lateral directions generated cyclical loading as shown in Figure 19. This cyclical loading may induce structural resonance depending on the natural frequency response of the turbine structure. Using 3D CFD simulations, cyclic force levels over each revolution, as well as their frequency, can be obtained, which when combined with natural frequency calculations may allow for the alleviation of any unwanted structural resonance effects. 


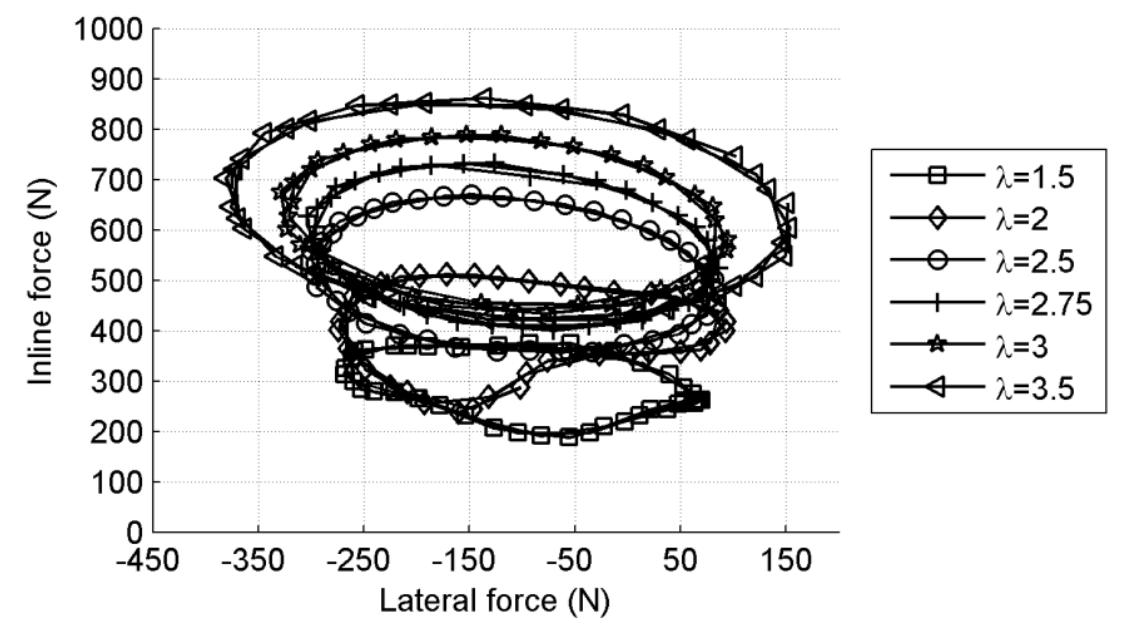

Figure 19: Cyclical mounting forces loading for $15^{\circ}$ blade overlap angle turbine for one revolution at an inflow velocity of $1.5 \mathrm{~ms}^{-1}$

\section{Conclusions}

The hydrodynamic performance of straight and helical bladed vertical axis turbines was investigated using validated 3D URANS CFD simulation models. Helicity was found to generate significant spanwise flow reducing lift and increased drag on the turbine blades. Thus straight bladed turbines, which by definition have a blade overlap of $0^{\circ}$ and thus no blade helicity, will generate the highest power output when compared to helically turbines of the same frontal area. The significance of this cannot be underestimated; straight bladed turbines exhibit higher power output when compared to helical bladed designs.

Although helical turbines exhibit lower power output than straight bladed turbines they offer some advantages. The curvature of the blades around the rotational axis was found to reduce torque oscillation and unsteady force loading levels. Differences in mounting forces were also determined between straight and helical bladed turbines, with reductions in force coefficients found for the helical bladed turbine as a result of the blade distribution around the rotational axis. The $15^{\circ}$ overlap helical turbine also generated vertical forces unlike the $0^{\circ}$ straight bladed counterpart again due to differences in blade distribution, although all vertical axis forces were not significant. For both turbines, the maximum forces were found to be more than $40 \%$ of the average.

This study reveals three key conclusions:

- straight bladed turbines generate higher power output than helical turbines;

- helical turbines are better at reducing torque oscillation levels and mounting forces, although the maximum power output will be reduced; and 
- blade section alignment to the inflow is not critical as long as the blade section is approximately perpendicular to the blade leading edge.

The 3D CFD models developed in this paper will be used to further investigate the blade loading of helical and straight bladed vertical axis turbines. As a result of the relationships between blade helicity and power output shown here only turbines with low blade overlaps will be investigated to maximise power generation capacity.

\section{Nomenclature}

$\begin{array}{llcl}C_{F M a x} & \text { Maximum force coefficient } & \text { Re } & \text { Reynolds number } \\ C_{F X} & \text { Inline force coefficient } & S & \text { Blade span [m] } \\ C_{F Y} & \text { Lateral force coefficient } & T R F & \text { Torque ripple factor } \\ C_{F Z} & \text { Vertical force coefficient } & V & \left.\text { Inflow velocity [ms } \mathrm{m}^{-1}\right] \\ C_{m} & \text { Moment coefficient } & y+ & \text { dimensionless distance of } 1^{\text {st }} \text { cell height to wall } \\ C_{m \text { Min }} & \text { Minimum moment coefficient } & \lambda & \text { Tip speed ratio } \\ C_{m} & \text { Maximum moment coefficient } & \phi & \text { Blade overlap angle } \\ C_{p} & \text { Power coefficient } & \rho & \text { Density }\left[\mathrm{kgm}^{-3}\right] \\ r & \text { Radius [m] } & \omega & \text { Rotation rate }\left[\mathrm{rads}^{-1}\right]\end{array}$

\section{References}

[1] I. Paraschivoiu

Wind Turbine Design: With Emphasis on Darrieus Concept

Polytechnic International Press (2002), Quebec, Canada

[2] A.R. Malipeddi, D. Chatterjee

Influence of duct geometry on the performance of Darrieus hydroturbine

Renewable Energy, 43 (2012), pp. 292-300

[3] J. Winchester, S.D. Quayle

Torque ripple and power in a variable pitch vertical axis tidal turbine

$9^{\text {th }}$ European Wave and Tidal Energy Conference (2011), Southampton, United Kingdom

[4] A. Gorlov

Helical Turbines for the Gulf Stream: Conceptual Approach to Design of a Large-Scale Floating Power Farm

Marine Technology and SNAME News, 35(3) (1998), pp. 175-182

[5] F. Scheurich, T.M. Fletcher, R. Brown

Simulating the aerodynamic performance and wake dynamics of a vertical-axis wind turbine Journal of Wind Energy, 14(2) (2010), pp. 159-177 
[6] M. Shiono, K. Suzuki, S. Kiho

Output Characteristics of Darreius Water Turbine with Helical Blades for Tidal Current Generation Proceedings of the Twelfth (2002) International Offshore and Polar Engineering Conference,

Kitakyushu, Japan

[7] A. Niblick

Experimental and Analytical Study of Helical Cross-Flow Turbines for a Tidal Micropower Generation System

Master's thesis (2012), University of Washington, Seattle, WA

[8] B.K. Kirke

Tests on ducted and bare helical and straight blade Darrieus hydrokinetic turbines

Renewable Energy, 36 (2011), pp. 3013-3022

[9] A. Gorlov

The Helical Turbine and its Applications for Hydropower without Dams

Proceedings of IMECE2002 ASME International Mechanical Engineering Congress and Exposition,

New Orleans, Louisiana, USA

[10] M. Castelli, E. Benini

Effects of Blade Inclination Angle on a Darrieus Wind Turbine

Journal of Turbomachinery, 134 (2012), pp. 031016-1-031016-10

[11] T.J. Hall

Numerical Simulation of a Cross Flow Marine Hydrokinetic Turbine

Master's thesis (2012), University of Washington, Seattle, WA

[12] G. Rawlings

Parametric Characterization of an Experimental Vertical Axis Hydro Turbine

Master's thesis (2008), University of British Columbia, BC

[13] P. Bachant

Experimental Investigation of Helical Cross-Flow Axis Hydrokinetic Turbines, including effects of Waves and Turbulence

Master's dissertation (2008), University of New Hampshire, New Hampshire, USA

[14] P. Bachant, M. Wosnik

Performance measurements of cylindrical- and spherical-helical cross-flow marine hydrokinetic turbines, with estimates of exergy efficiency

Renewable Energy, 74 (2015), pp. 318-325

[15] Ansys Inc.

ANSYS CFX-Solver Theory Guide: Release $\mathbf{1 3 . 0}$

Ansys Inc. (2010), Canonsburg, PA, USA

[16] F.R. Menter

Two-Equation Eddy-Viscosity Turbulence Models for Engineering Applications

AIAA J, 32(8) (1994), pp. 1598-1605 
[17] P. Marsh, D. Ranmuthugala, I. Penesis, G. Thomas

Performance predictions of a straight-bladed vertical axis turbine using double-multiple streamtube and computational fluid dynamics

The Journal of Ocean Technology, 8(1) (2013), pp. 87-103

[18] P. Marsh, D. Ranmuthugala, I. Penesis, G. Thomas

Three dimensional numerical simulations of a straight-bladed vertical axis tidal turbine

Proceedings of the $18^{\text {th }}$ Australasian Fluid Mechanics Conference (2012), Launceston, Tasmania

[19] Y.M Dai YM, W. Lam

Numerical Study of Straight-Bladed Darrieus-Type Tidal Turbine

Proceedings of the institution of civil engineers, Energy 162(2) (2009), pp. 67-76

[20] S. Lain

Simulation and Evaluation of a Straight-Bladed Darrieus-type Cross Flow Marine Turbine

Journal of Scientific and Industrial Research, 69(12) (2010), pp. 906-912

[21] G.I. Gretton

Hydrodynamic analysis of a vertical axis tidal turbine

PhD thesis (2009), University of Edinburgh, Edinburgh, UK

[22] J.D. Anderson

Fundamentals of Aerodynamics: Second Edition

McGraw-Hill Education, 2010

[23] N. Sorensen

CFD Modelling of Laminar-turbulent Transition for Airfoils and Rotors Using the $\boldsymbol{\gamma}-\mathrm{Re}_{\boldsymbol{\theta}}$ Model Wind Energy, 12(8) (2009), pp. 715-733

[24] M.R. Castelli, G. Ardizzon, L. Battisti, E. Benini, G. Pavesi

Modeling strategy and numerical validation for a Darrieus vertical axis micro-wind turbine

ASME 2010 International Mechanical Engineering Congress and Exposition (2010), Vancouver, British

Columbia, Canada

[25] K.W. McLaren

A numerical and experimental study of unsteady loading of high solidity vertical axis wind turbines Master's thesis (2011), McMaster University, Ontario, Canada

[26] T. Maitre, E. Amet, C. Pellone

Modeling of the flow in a Darrieus water turbine: Wall grid refinement analysis and comparison with experiments

Renewable Energy, 51 (2013), pp. 497-512

[27] L.A. Danao

The influence of Unsteady Wind on the Performance and Aerodynamics of Vertical Axis Wind Turbines

PhD dissertation (2012), University of Sheffield, UK 
[28] Y. Li, S.M. Calisal

Numerical analysis of the characteristics of vertical axis current turbines

Renewable Energy, 35 (2010), pp. 435-442

[29]Y. Nabavi

Numerical Study of the Duct Shape Effect on the Performance of a Ducted Vertical Axis Tidal Turbine

Masters dissertation (2008), University of British Columbia.

[30] J. Winchester, SD Quayle

Torque ripple and power in a variable pitch vertical axis tidal turbine

$9^{\text {th }}$ European Wave and Tidal Energy Conference (2011), Southampton, UK 